\title{
PEG Brush Peptide Nanospheres with Stealth Properties and Chemical Functionality
}

\author{
Tomonori Waku, ${ }^{1}$ Michiya Matsusaki, ${ }^{1}$ Tatsuo Kaneko, ${ }^{1}$ and Mitsuru Akashi ${ }^{1,2}$ \\ ${ }^{1}$ Department of Applied Chemistry, Graduate School of Engineering, Osaka University, \\ 2-1 Yamada-oka, Suita 565-0871, Japan \\ 2Core Research for Evolutional Science and Technology (CREST), Japan Science and Technology \\ Agency (JST), 4-1-8 Honcho, Kawaguchi-shi 332-0012, Japan \\ E-mail: akashi@chem.eng.osaka-u.ac.jp.
}

\section{Contents:}

1. Evaluation of the Molecular Weight of the Peptide Nanospheres

2. Hemolytic Activity of the Peptide Nanospheres 


\section{Evaluation of the Molecular Weight of the Peptide Nanospheres}

In the previous report, we estimated the average molecular weight of the peptide nanospheres in hexafluoroisopropanol (HFIP) by GPC measurements. ${ }^{1}$ The peptide nanospheres were dissolved in HFIP, and the solution was transparent. The molecular weight showed two sharp peaks at $M_{\mathrm{w}}=$ $17,590\left(M_{\mathrm{w}} / M_{\mathrm{n}}=1.06\right)$ and $6,060\left(M_{\mathrm{w}} / M_{\mathrm{n}}=1.04\right)$, and we concluded that the higher and lower molecular weight components were the $\mathrm{p}(\mathrm{Phe}-b-\mathrm{EG})$ copolymer and the Phe homopolymer, respectively, based on viscosity experiments. For multivalent evaluation of the molecular weights of the Phe homopolymer and $\mathrm{p}$ (Phe- $b$-EG) copolymer, ${ }^{1} \mathrm{H}-\mathrm{NMR}$ and MALDI-TOF mass analyses were performed. The peptide nanospheres (Table 1 , run 4) were dissolved in chloroform- $d /$ TFA- $d$ (4/1 $\mathrm{v} / \mathrm{v}$ ), and the ${ }^{1} \mathrm{H}-\mathrm{NMR}$ spectrum was measured at $25{ }^{\circ} \mathrm{C}$ (Figure $\mathrm{S} 1{ }^{1}$ ). It is difficult to determine the individual molecular weights of the Phe homopolymer and the $\mathrm{p}\left(\mathrm{Phe}-b\right.$-EG) copolymer from the ${ }^{1} \mathrm{H}$ NMR spectra because both polymers contain Phe segments. However, the molar ratio of the total Phe units, $\mathrm{NH}_{2}$-PEG-OCH 3 and $\mathrm{BA}$ were calculated as $37.3: 1.0: 2.3$ from the integrated values of the $\mathrm{CH}$ peaks at 4.4 and $4.6 \mathrm{ppm}$, the terminated $\mathrm{CH}_{3}$ peak at $3.5 \mathrm{ppm}$ and the terminated $\mathrm{CH}_{3}$ peak at $0.9 \mathrm{ppm}$, belonging to the Phe segments $\mathrm{NH}_{2}-\mathrm{PEG}-\mathrm{OCH}_{3}$ and $\mathrm{BA}$, respectively. However, the total molar ratio of Phe units and $\mathrm{NH}_{2}-\mathrm{PEG}-\mathrm{OCH}_{3}$ estimated from the GPC measurements was about 106 : 1.0, and was vastly different from the results of the ${ }^{1} \mathrm{H}-\mathrm{NMR}$ measurement.

The MALDI-TOF mass spectra (MS) of the peptide nanospheres were measured by a VoyagerTM RP system (PerSpective Biosystems) using a nitrogen laser $(\lambda=337 \mathrm{~nm})$. The irradiation targets were prepared from solutions of the peptide nanospheres in $\mathrm{CHCl}_{3} / \mathrm{TFA}(4 / 1 \mathrm{v} / \mathrm{v})$ with dithranol as the matrix and $\mathrm{K}^{+}$-trifluoroacetate as the dopant. In addition to the $\mathrm{K}^{+}$-doped masses, the peaks of $\mathrm{H}^{+}$- and $\mathrm{Na}^{-}$- doped nanospheres were also detectable in the MS. Figure S2 shows the MS spectra of the peptide nanospheres (Table 1, run 4). Many peaks from 1,141 to 2,906 mass at intervals of 147 were observed, and all peaks were assigned to Phe homopolymers containing 7 to 19 repeating units of Phe segments. Although the peptide nanospheres consisted of Phe homopolymer and $\mathrm{p}$ (Phe- $b$-EG) 
copolymer, only the Phe homopolymers were detected because we used dithranol, which is the optimum matrix for poly(phenylalanine) based on the report from Kricheldorf and coworkers. ${ }^{2}$ From the results of the MS analysis, the molecular weight of the Phe homopolymer in the peptide nanospheres was elucidated to be about 1,000 to 3,000; the average molecular weight was ca. 2,000 containing 13 repeating units of Phe segments. The ${ }^{1}$ H-NMR measurement of the peptide nanospheres indicated the molar ratio of total Phe units, $\mathrm{NH}_{2}-{ }_{-\mathrm{PEG}-\mathrm{OCH}_{3}}$, and $\mathrm{BA}$, as 37.3 : $1.0: 2.3$, respectively. The 2.3 molar ratio of $\mathrm{BA}$ indicated the existence of the 2.3 molar ratio of PPhe homopolymer. Therefore, the DP of Phe units in p(Phe- $b$-EG) (initiated from NH $2=$ $\underline{\text { PEG-OCH }} 3)$ should be calculated as follows: $37.3-(2.3 \times 13)=7.4$. Accordingly, we estimated the DP of PPhe and p(Phe- $b$-EG) to be 13 and 7.4, respectively. These results from the ${ }^{1} \mathrm{H}-\mathrm{NMR}$ and MALDI-TOF mass spectra differed greatly from the results of GPC measurements, and the main reason seems to be that the peptide nanospheres were not completely dissolved in the HFIP (GPC solvent), even though the dissolving solvent was transparent. Actually, the molecular weight of the Phe homopolymer (Table 1, run 1) or $\mathrm{p}(\mathrm{Phe}-\mathrm{b}-\mathrm{EG})$ copolymer (Table 1, run 7) synthesized from a solitary initiator BA or NH2-PEG-OCH3 was about 2,000 to 4,000, containing 7 to 15 repeating Phe units based on ${ }^{1} \mathrm{H}-\mathrm{NMR}$ measurements in chloroform- $d /$ TFA-d (4/1 v/v) (data not shown). Furthermore, Kricheldorf reported that the solubility of poly(phenylalanine) was extremely decreased at over 4 repeating units. ${ }^{3}$ Accordingly, we concluded that the synthesis of the Phe homopolymer and $\mathrm{p}$ (Phe- $b$-EG) copolymer at high molecular weight was difficult under our reaction conditions because of their solubility, and the dissolving peptide nanosphere components in the HFIP solvent seemed to form the micelles aggregates due to the amphiphilic property of the $\mathrm{p}(\mathrm{Phe}-b-\mathrm{EG})$ copolymer. In fact, the DLS measurement of the dissolving peptide nanosphere in HFIP indicated the formation of aggregates like a micelle having ca. $160 \mathrm{~nm}$ of the diameter. The

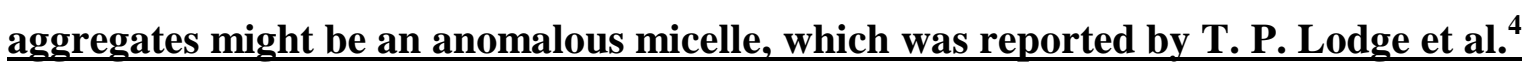



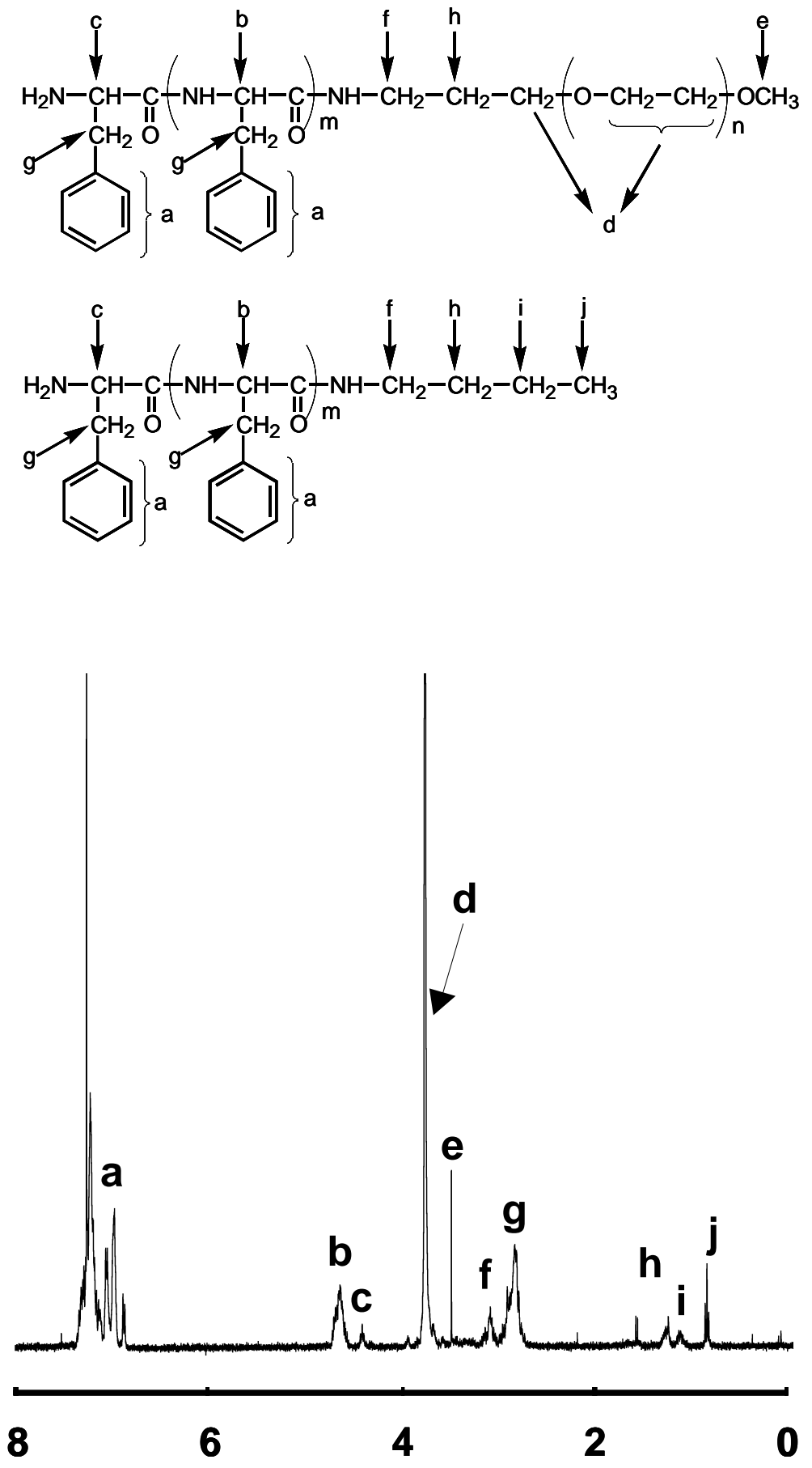

\section{$\delta(\mathrm{ppm})$}

Figure S1. ${ }^{1} \mathrm{H}-\mathrm{NMR}$ spectrum 4 of the peptide nanospheres (NS$2 \mathrm{k}-\mathrm{OCH}_{3}$; Table 1 , run 4) in TFA- $d /$ chloroform- $d(1 / 4 \mathrm{v} / \mathrm{v}){ }^{1}$ 


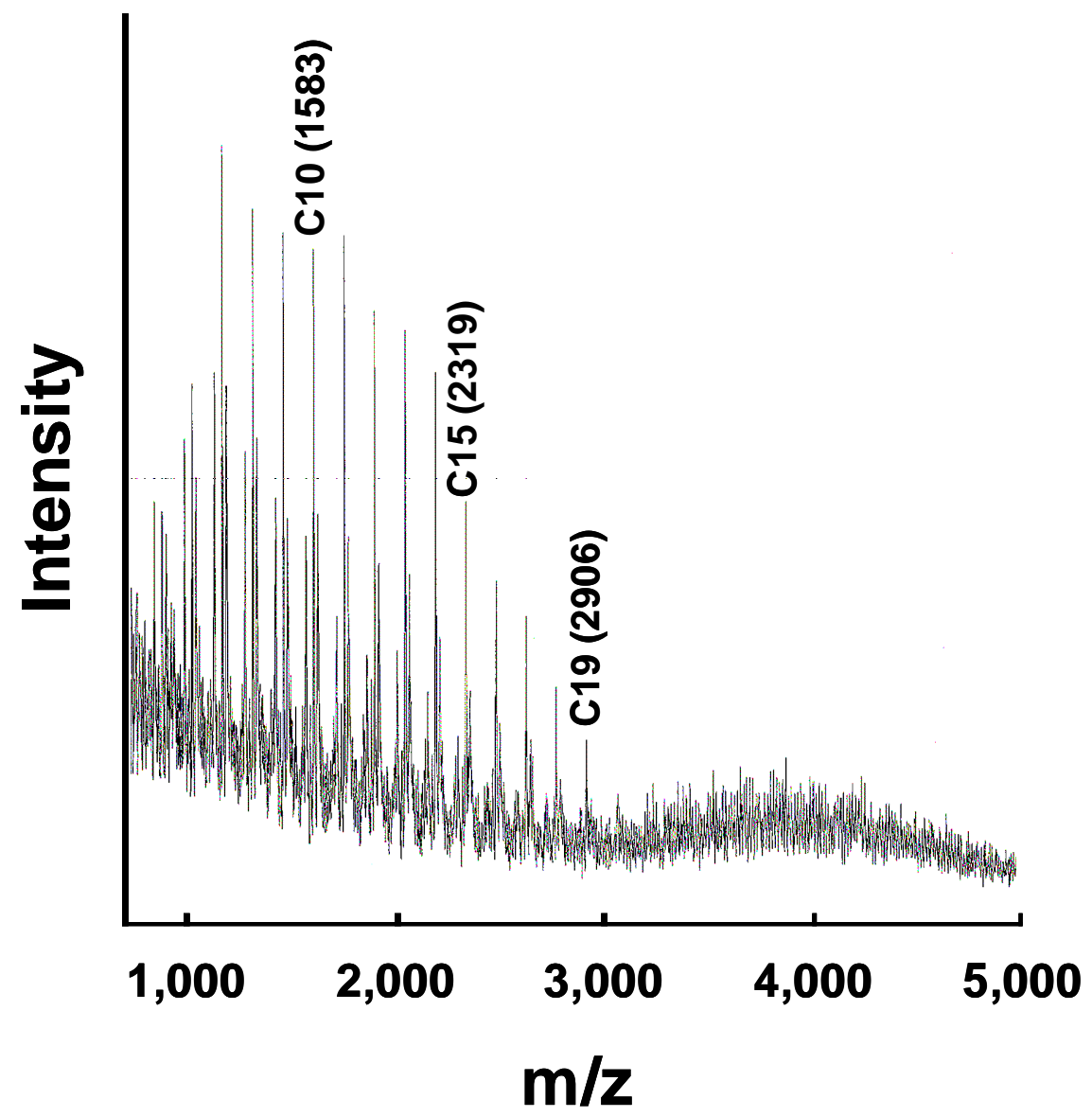

Figure S2. MALDI-TOF mass spectrum of the peptide nanospheres (NS-2k-OCH 3 ; Table 1, run 4). 


\section{Hemolytic Activity of the Peptide Nanospheres}

We evaluated the hemolytic activity of the peptide nanospheres (NS-3.4k-COOH; Table 1, run 17) using red blood cells (RBCs). The peptide nanospheres were dispersed in 2-(Nmorpholino)ethanesulfonic acid (MES) buffer ( $\mathrm{pH}$ 5.0-7.5) at $2 \mathrm{mg} / \mathrm{mL}$ and incubated with equivalent volume of $2 \times 10^{8}$ cells $/ \mathrm{mL} \mathrm{RBCs} \mathrm{solution} \mathrm{at} 37{ }^{\circ} \mathrm{C}$ for $1 \mathrm{~h}$. After the removal of RBCs, the amount of hemoglobin in the supernatant was determined by measuring the absorbance at $570 \mathrm{~nm}$. The hemolysis were $2.8-4.5 \%$ at $\mathrm{pH} 5.0-7.5$ as shown in Figure S3. These results indicated that the peptide nanospheres were not interacted with RBCs, suggesting the stealth properties of the nanospheres.

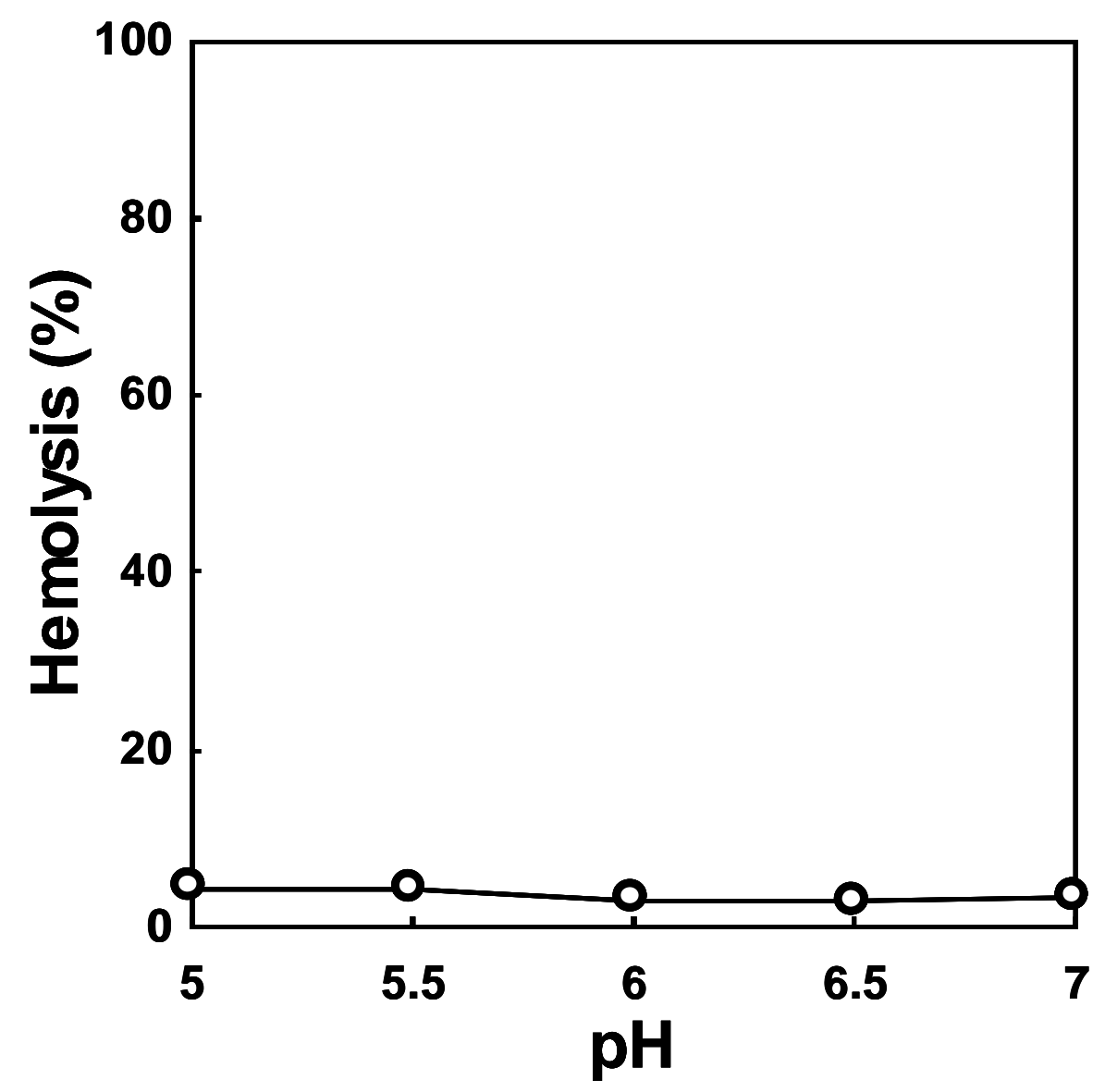

Figure S3. Hemolytic activity of the peptide nanospheres (NS-3.4k-COOH; Table 1, run 17). RBCs were incubated with $1 \mathrm{mg} / \mathrm{mL}$ of the peptide nanospheres for $1 \mathrm{~h}$ at $37{ }^{\circ} \mathrm{C}$ in 25 mM MES buffer (pH 5-7) containing $0.15 \mathrm{M} \mathrm{NaCl}$. 


\section{References for Supporting Information}

1) Matsusaki, M.; Waku, T.; Kaneko, T.; Kida, T.; Akashi, M. Langmuir 2006, 22, 1396-1399.

2) Kricheldorf, H. R.; Lossow, C.; Schwarz, G. Macromolecules 2005, 38, 5513-5518.

3) Kricheldorf, H. R. Makromol. Chem. 1983, 184, 1407-1421.

4) Lodge, T. P.; Bang, J.; Hanley, K. J., Krocak, J., Dahlquist, S.; Sujan, B.; Ott, J. Langmuir 2003, 19, 2103-2109. 